\title{
Microbial deterioration of clay roofing tiles
}

\author{
M. Radeka ${ }^{1}$, J. Kiurski $^{1}$, S. Markov ${ }^{2}$, R. Marinković-Nedučin ${ }^{2}$ \\ \& J. Ranogajec ${ }^{2}$ \\ ${ }^{1}$ Faculty of Technical Sciences, University of Novi Sad, Serbia \\ ${ }^{2}$ Faculty of Technology, University of Novi Sad, Serbia
}

\begin{abstract}
The study illustrates both the biodeterioration and biomineralization actions of two fungus species (Aspergillus niger and Cladosporium sp.) and two organic acids (oxalic and acetic) and the action of the frost (frost dilatation studies in laboratory conditions) as the main factors of the process of ageing of clay roofing tiles. The nano-crystalline products, formed in this way, contribute to the abundant reactive surface area of the existing and new filled pores (due to the fungus hyphen penetration into the ceramic support) deepening the ageing processes of the clay roofing tiles.

A relationship between the textural and microstructural characteristics of the studied systems and the formation of the specific crystal forms, developed after the actions of fungus, and oxalic/acetic acids was set up.

Keywords: biodeterioration, lichen, fungi, oxalic acid, acetic acid, clay roofing tiles.
\end{abstract}

\section{Introduction}

Cultural heritage objects were made with almost all type of materials produced by nature and used by men to realize several types of artefacts of very simple mono-components and of complex structure, integrating inorganic and organic matter. These objects, even if they were made of more "resistant" stones, mortars and ceramic materials, are influenced by the environmental parameters, which can modify their structure and composition. Furthermore, inserted into the "biosphere" they can be decayed by biological mechanisms. Clay roofing tiles, as a part of this world, support large and diverse communities of microorganisms that colonize both the tile surface and the porous interior. Their weathering, as a result of organic acid exudation by lichens, fungi and bacteria, is recognized as a 
biogeochemical process. The vast diversity of microorganisms growth requirements, as their response to the environmental stress factors, causes difficulties in definding the right mechanism of bio-corrosion of the considered ceramic system.

The chemical composition and the physical characteristics of clay roofing tile surfaces change over the time of exposure to weather. A certain aspect of material transformation is due to the metabolic activity connected with the growth of living organisms. The growth process and, consequently, the vegetable development of organisms have a direct consequence on the aesthetics effect. In general, the kind of biological agent that develops on clay roofing tiles is affected by the clay type (alkaline or acidic clay type) and their surface conditions, together with the environmental location and the climate to which the clay roofing tiles are exposed [1].

The weathering of the clay roofing tiles, described in this paper, was simulated in laboratory conditions: by the submerging of the ceramic samples in organic acids (acetic and oxalic acid) of the define concentration (4 mass. \%), by the inoculation of their surface with two species of fungus culture (Aspergillus Niger and Cladosporia) as well as by their exposure to temperature fluctuations. The choice of fungus was done after the lichenological analysis of the aged clay roofing tiles collected in the north-east area of Serbia, region of Novi Becej, while the choice of the acids concentration was done based on our previous investigation $[2,3]$. The identification of crystal forms, produced by the action of the inoculated fungus, made possible a better understanding of lichens effect on the ceramic support. The analysis of the results obtained after the actions of oxalic and acetic acids (main components of the lichen/fungus excretion) gave closer information about the textural changes during ceramic material weathering.

\section{Materials and methods}

\subsection{Aged ceramic roofing tiles}

Aged ceramic roofing tiles (aged 30 years) collected from five different locations, the north-east of Serbia, Novi Becej region [3]. Their ceramic surface coated with lichens was analysed with a light microscope and identified in accordance with Gollerbah [4].

\subsection{Fresh ceramic samples}

Laboratory prepared ceramic system - (size $12 \times 8 \times 0.8 \mathrm{~cm})$ [4]. The raw material used for the tiles preparation was the clayey material with a considerable amount of quartz, plagioclase, mica and traces of carbonates $[2,3]$. The first series of the segments of the laboratory made tiles was inoculated with the fungus (Aspergillus niger and Cladosporium sp.), while the second was separately 
immersed in $4 \mathrm{wt} \%$ of oxalic/acetic acid (time of immersion 50 days). These experiments started from the fact that the lichen is a symbiotic life form between a fungus and an alga or cyanobacteria excreting organic acids while metabolizing the inorganic compounds of the ceramic system. It was the fungal component of this symbiotic association that the acidolytic and complexing activity shown by the lichens was due to. The reduction and oxidation of the mineral cations are the consequences of the activities of the fungi, which ends with new crystal formations.

The samples of roof tiles were cut into pieces $(3 \times 2 \times 0.8 \mathrm{~cm})$ and their lateral sides were covered with a thin layer of parafine. Each sample was placed into a Petri dish which contained $3 \mathrm{~cm}^{3}$ sterilized destilated water. On the top surface was pippeted $0.1 \mathrm{~cm}^{3}$ sterilized soil exstract [5] as a environment medium for fungus growth and seeded with $0.05 \mathrm{~cm}^{3}$ suspension of Aspergillus niger / Cladosporium sp. spores. During the incubation period (time of immersion 90 days) at a room temperature $\left(20-22^{\circ} \mathrm{C}\right) 1 \mathrm{~cm}^{3}$ sterilized destilated water was added periodicaly (every 30 days) into bottom of the Petri dish to maintain humidity. The control samples were prepared and incubated in the same way, without the addition of growth medium and fungal spores.

The ceramic systems characterization, before and after the action of oxalic and acetic acids, and after 50 days of inoculation with the fungus, were performed by the following methods: SEM and EDS investigation, JEOL JSM6460LV (Tokyo, Japan); Hg-porosimetry, Porosimeter Carlo Erba 2000 (Rodano, Milano, Italy); Low temperature nitrogen adsorption, Model 2000, (ASAP Micrometrics, USA) and Low temperature dilatation, Thermo Mechanical Analyser, Du Pont (Delaware, USA).

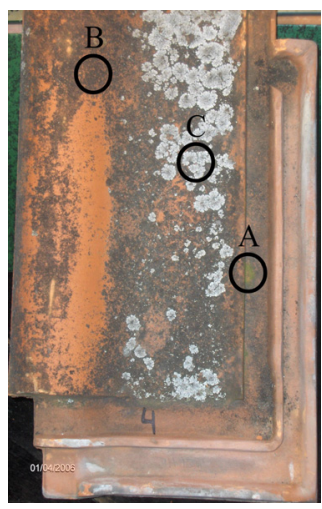

(a)

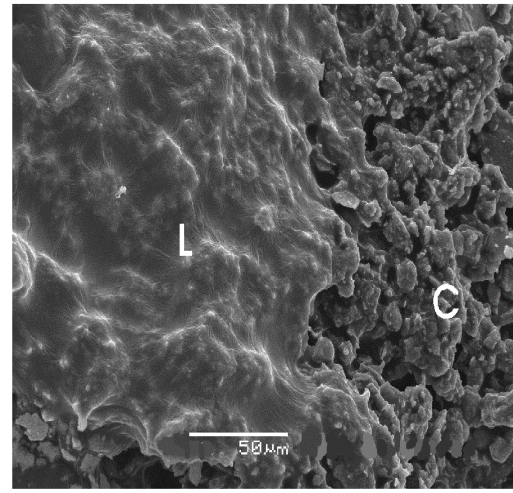

(b)

Figure 1: (a) Image of aged ceramic roofing tile with microorganism's communities. (b) The lichen biofilm-ceramic tile interface (L-C), fig.1 (a) - detail B. SEM micrograph (x 500). 


\section{Results and discussion}

\subsection{Aged ceramic roofing tiles}

By the lichenological analysis the presence of algae and cianobacteria have been determined on the flopping part of the tiles (fig. 1(a) - detail A), while Verrucaria nigrescens (fig. 1(a) - detail B) has been identified as the most dominant lichen on the surface of the ceramic tiles (occupying 30\% of the whole free surface). The lichen thallus is attached to the ceramic substrate by the hyphaes, as shown in the transverse section of the lichen-ceramic tile interface, fig. 1(b), forming a thin biofilm usually described as patina. The next lichen, identified on the same tiles, was Endocarpon pusillum (fig. 1(a) - detail C) with a completely formed thallus (radius $3-4 \mathrm{~cm}$ ) [3].

\subsection{Laboratory ceramic systems}

The combination of SEM and EDS techniques was a very adequate and complementary tool in the study of the fungus-ceramic tile interface. The application of these techniques fulfils the possibility of carrying out the chemical analysis of the new formations in tiles "in situ" after a relatively short-term action of the fungi (90 days). It was also possible to clarify the doubts about the nature of the interphases formed after the action of the acids secreted by the fungi. The low temperature dilatation technique enabled the prediction of the frost resistance characteristics of the samples immersed in oxalic and acetic acid and after submerged $24 \mathrm{~h}$ in water (water saturated samples).

\subsubsection{Roofing tiles inoculated with Aspergillus niger}

Poorly ordered alumino-silicates, intimately admixed with Ca-alumino-silicates, the main crystal forms of the tiles, fig. 2(a), fig. 2(b) and fig. 2(c), Part 1, were partially decomposed due to the metabolic activity of the fungus. That presented a good basis for the next steps: formation of two calcium oxalate forms (whewellite, weddellite), fig. 2(c), part 2.

It is well known that it is necessary for a fungus to dispose of the excess of calcium (metabolic activity), the fact that probably presents the main reason for the formation of the calcium oxalate deposits. Considering our model of inoculation, the first form of Ca-oxalate, recognized as bypiramidal crystals calcium oxalate dehidrate ( $\mathrm{HO})$, was registered in the close vicinity of the hyphae (H), fig. 3, which after a certain period of time, losing a water molecule, takes the form of platy crystals (TO). The calcium oxalate monohydrate (TO) formed in these circumstances fulfilled the pore spaces changing the surface characteristics of the sample. It presented the start of the biofilm formation which accelerates the weathering of the tile samples.

\subsubsection{Roofing tiles inoculated with Cladosporium sp.}

The original existence of calcium in the ceramic support, inoculated with Cladosporium sp. spores, fig. 4, presented the driving force of the further calcium oxalate formations. These crystal forms were created in large amounts in 


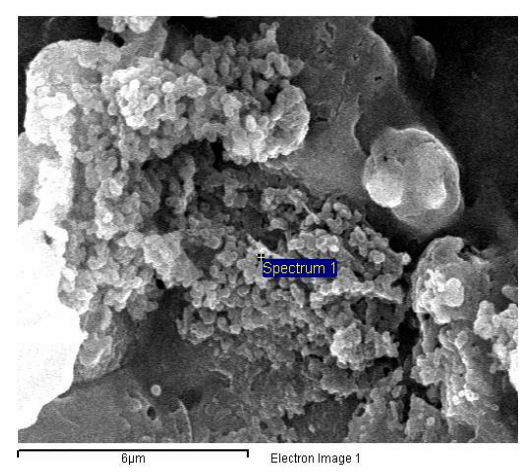

(a)

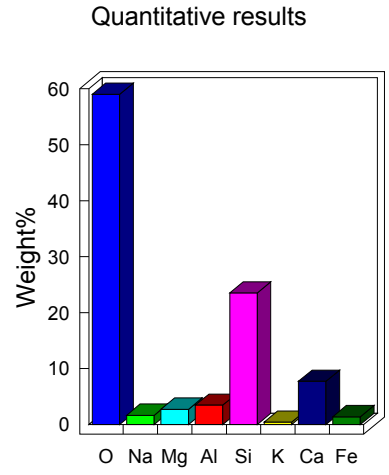

(b)

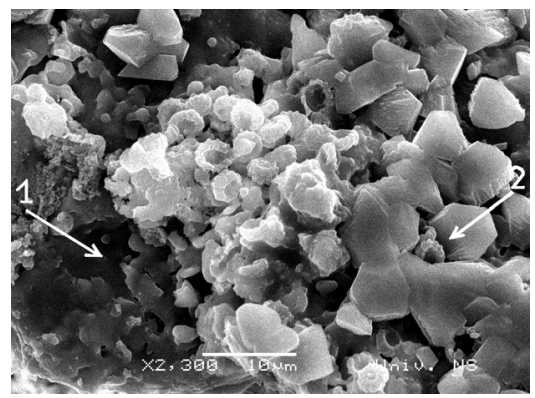

(c)

Figure 2: $\quad$ SEM micrograph of the selected areas of the laboratory ceramic systems inoculated with Aspergillus niger (a) x 10000 and (c) x 2300). Quantitative results of the presence of the elements $\mathrm{O}$, $\mathrm{Si}, \mathrm{Ca}, \mathrm{Al}, \mathrm{Mg}, \mathrm{Na}, \mathrm{Fe}, \mathrm{K}$, in the spectrum 1. (b).

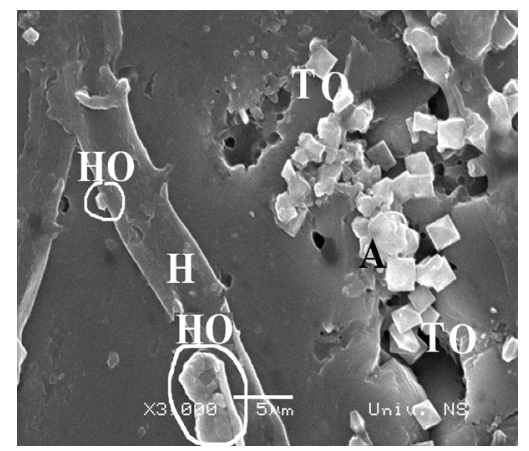

Figure 3: Bypiramidal crystals - calcium oxalate dehidrate (HO) registered in the close vicinity of the hyphae $(\mathrm{H})$ and the platy crystals of calcium oxalate monohydrate (TO). SEM micrograph, x 3000. 
the biofilm intensified on the surface of the analysed systems. Despite the relatively low solubility of calcium oxalate formation (by several orders lower than that of calcium carbonate, including calcite and dolomite), it was quite rapidly transformed into the calcite form in the course of biodeterioration and biotransformation of the tile surface, fig. 4(b).

\section{Quantitative results Quantitative results}

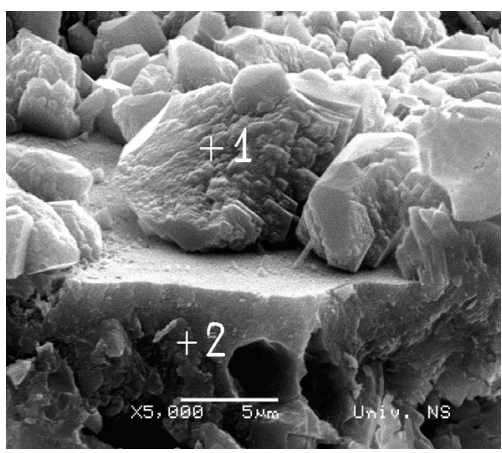

(a)

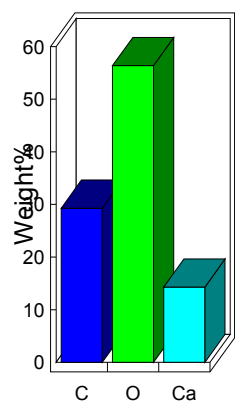

Spectrum 1.

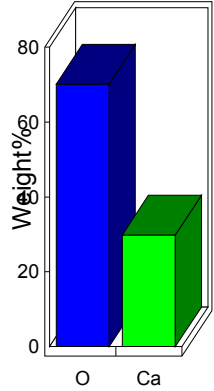

Spectrum 2.

(b)

Figure 4: SEM micrograph of the ceramic sample after the action of Cladosporium sp., x 5.000. Calcium carbonate deposits on the tile surface (a) and the quantitative results of the presence of the elements: $\mathrm{C}, \mathrm{O}, \mathrm{Ca} / \mathrm{O}, \mathrm{Ca}$, in the spectrums 1. and 2. (b).

Undoubtedly, the hyphen penetration of both fungi into the ceramic substrate presented the beginning of the physical deterioration of the tile which continues with the biochemical weathering. The removal of one kind of elements ( $\mathrm{Al}, \mathrm{Si}$, $\mathrm{Fe}$ and $\mathrm{K}$ ), fig. 2(a), and the accumulation of the others (C and $\mathrm{Ca}$ ), figs. 4 and 5, presented the basis of the phase changes in the case of the studied tile samples made in laboratory (samples free of textural faults). The oxalic acid secreted by the fungi played the crucial role in the removal actions of the elements. This acid could be taken as the most important agent of the deterioration process in the case of our systems, but not the unique one. The fungi also secrete other simple organic acids, such as acetic, citric and gluconic, which can also lead to the weathering of the ceramic support through acidic attack and chelation [1]. leading to the formation of the biofilm and to the biopitting changes of the ceramic surface, fig. 5. In the upper part of the biofilm, obtained after the action of Cladosporium sp., Ca oxalate forms were transformed into calcite, fig. 5(b). The biopitting phenomenon in the vicinity of this area was identified. Namely, by the dieing of the fungus, the pitting corrosion with etched negative image pattern was left behind. Moreover, the action of the fungus can end with a plugging effect due to the metabolic activity and to the incorporation of the mineral fragments into its thallus [6]. 


\section{Quantitative results}

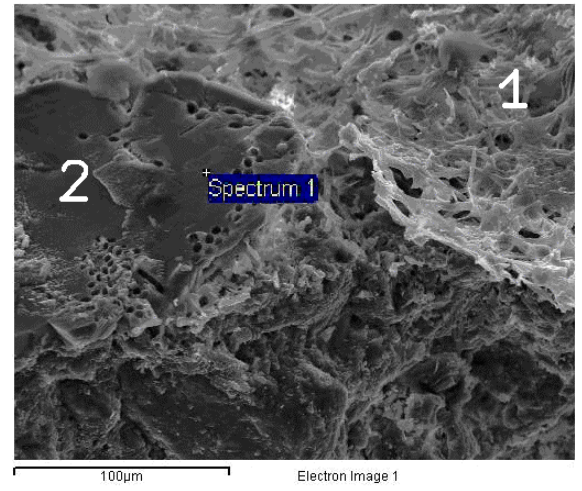

(a)

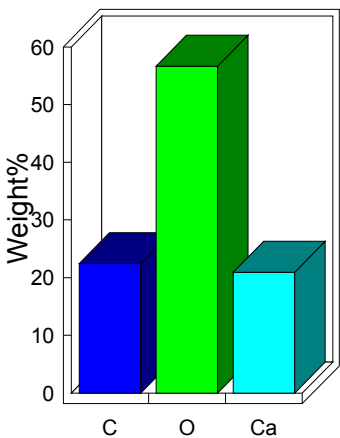

(b)

Figure 5: (a) SEM micrograph of the tile surface covered with the fungus (Cladosporium) hypae (part 1) and the biofilm (part 2), (b) quantitative results of the presence of the elements $\mathrm{O}, \mathrm{Ca}$ and $\mathrm{C}$ in the spectrum 1 (EDS analysis).

\subsubsection{Laboratory ceramic system immersed in oxalic and acetic acid}

The influence of low concentration of oxalic acid (0.01 and $0.1 \mathrm{wt} \%)$ on the changes of textural characteristics and freezing dilatation values of the laboratory ceramic samples had already been examined [3]. By encircling the wall pores with the layers of calcium oxalate, the oxalic acid had shown a positive effect on the total linear dilatation values of the ceramic tile (no brusque linear dilatation changes were noticed in the case of non acid immersed ceramic system). Considering the experiments with the samples immersed in $4 \mathrm{wt} \%$ of oxalic acid, fig. 6(a), no spectacular changes could be noticed, fig. 6, in comparison with the ones immersed in lower concentrations. The maximum of the dilatation value is the same $\left(\Delta \mathrm{L} / \mathrm{L} 10^{-4}=2\right)$ ending with a slow decrease during the thawing procedure within the interval of $-10^{\circ}$ up to $+10^{\circ} \mathrm{C}$, fig. 7. This is the consequence of the relaxed tension of the tile structure whose pores were encircled with Ca-oxalate crust, the fact that influences the decrease of the total porosity of the samples, table 1, giving a massive structure to the tile, fig. 6(a).

Table 1: Total porosity values and dominant pore intervals for the referent and tiles treated with acids.

\begin{tabular}{|l|c|c|}
\hline \multicolumn{1}{|c|}{ Sample } & Total porosity $(\%)$ & Dominant pore $(\mu \mathrm{m})$ \\
\hline Referent tile & 32.93 & $0.5-1$ \\
\hline $\begin{array}{l}\text { Tile immersed in } \\
\text { 4\% oxalic acid }\end{array}$ & 26.16 & $2-4$ \\
\hline $\begin{array}{l}\text { Tile immersed in } \\
\text { 4\% acetic acid }\end{array}$ & 36.09 & $0.5-1$ \\
\hline
\end{tabular}




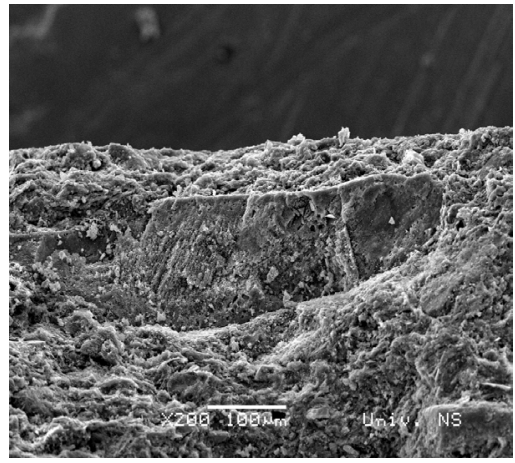

(a)

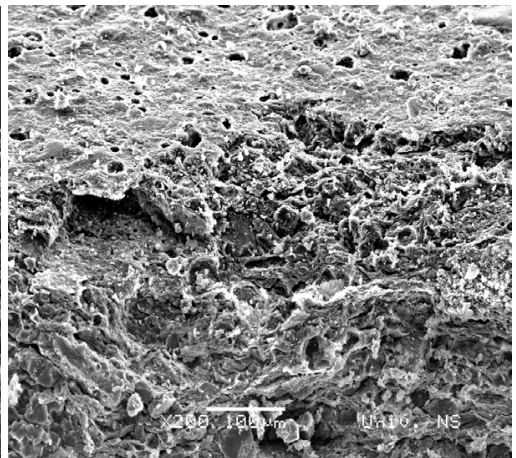

(b)

Figure 6: SEM micrographs of the samples of a tile after 50 days of oxalic (a), acetic acid action (b), x 200.

The action of acetic acid was different from the one shown by the oxalic acid: the total porosity of the system was increased as well as the dilatation value of the sample tile in the temperature interval $-40^{\circ} \mathrm{C}$ up to $-10^{\circ} \mathrm{C}$. The unstable form of the $\mathrm{Ca}$-acetate (formed after the action of acetic acid) within the analyzed temperature interval influenced the pore structure formation on the tile surface, fig. 6(b), and consequently, there was an increase of the low temperature dilatation value, fig. 7 .

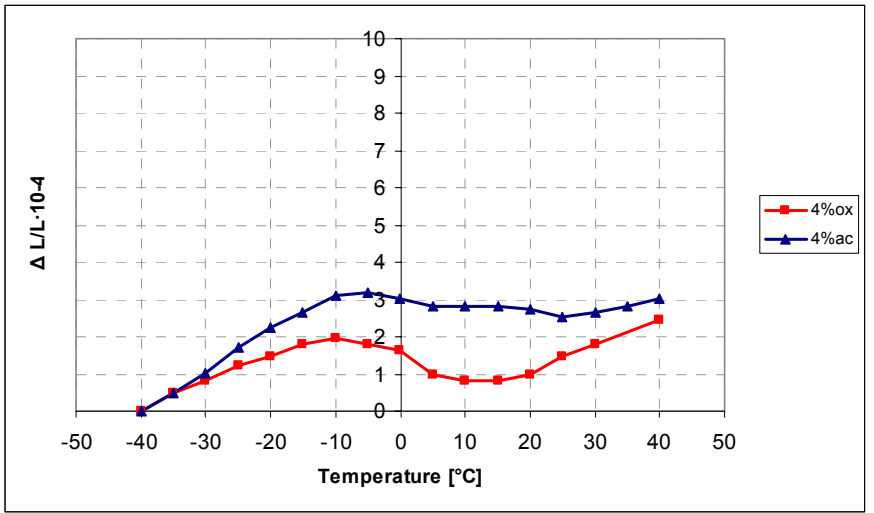

Figure 7: Low temperature dilatation values of the samples of ceramic tiles after the action of $4 \% \mathrm{wt}$ of oxalic acid/acetic acid within the temperature dilatation $-40^{\circ} \mathrm{C} \div+40^{\circ} \mathrm{C}$.

\section{Conclusions}

Two different models, ceramic tile samples inoculated with the fungi (Aspergillus niger and Cladosporium sp.) and ceramic tile samples immersed in 
oxalic and acetic acids (4\%wt) were examined for the estimation of lichen actions on the surface of ceramic roofing tiles. It was shown that the genesis of the initial texture degradation of the ceramic support, after the action of modeled fungus, depended on the removal of the elements from one part of the surface tile to the other. This phenomenon supported the creation of the particular calcium oxalate forms. Platy crystals of calcium oxalate monohydrate, whewellite, were formed in the close vicinity of the hyphen, while bypiramidal crystals of calcium oxalate dehydrate, weddellite, were identified in the interior of the porous structure of the tile and on the tile surface. The textural characteristics of the ceramic samples changed in accordance with the nature of the acid in which the sample was immersed. This fact dictated the crystals type formation which, encircling the pore wall, determined the final depleted form of the tile sample. The acetic acid action brought about a more porous structure than in the case of the oxalic action. The oxalic crust played a protective role in the case of frost action ( $24 \mathrm{~h}$ submerged samples before the low temperature action).

\section{References}

[1] Sand, W., Microbial mechanisms of deterioration of inorganic substrates - A General mechanistic overview. International Bioderioration and Biodegradation, 40/2-4,183-190, 1997.

[2] Radeka, M., Ranogajec, J., Kiurski, J., Markov, S., \& Marinković-Nedučin, $\mathrm{R}$., Influence of lichen biocorrosion on the quality of ceramic roofing tiles, Journal of the European Cermic Society, 27, 1763-1766, 2007.

[3] Kiurski, J., Ranogajec, J., Marinković-Nedučin, R., Markov, S., \& Bačkalić, Z., Aging processes of ceramic roofing tiles due to the lichem actions, Reliability of Ceramics, ECERS Topical Meeting, Krakow, Poland, pp.30, 2006.

[4] Gollerbah, M.M.,Vodorosli, Lishajniki, Prosveshenie, Moskva, pp. 379-471, 1977.

[5] Johnson, L.F., Curl, E.A., Bond, J.H., \& Fribourg, H.A., Method for studying Soil microflora-plant disease relationship, Burgess Publ. Co., Mineapolis, pp.145, 1960.

[6] Prieto, B., Silva, B., Rivas, T., Wierzchos, J. \& Ascso, C., Mineralogical transformation and neoformtion in granite caused by lichens Tephromela atra and Ochrolecia parella, International Biodeterioration and Biodegradation 40, 193-199, 1997. 